\title{
Extinction of fear memory during development: lesson for a better exposure therapy?
}

\author{
Liyu Li and Qiang Zhou* \\ School of Chemical Biology and Biotechnology, Peking University Shenzhen Graduate School, Shenzhen, China
}

\begin{abstract}
A large number of behavioral studies have shown that extinction does not eliminate the classical fear memory in the adult. The majority of studies have focused on the mechanisms of extinction-induced inhibition within the fear circuits. However, recent studies have uncovered mechanisms that destabilize and perhaps even erase fear memories, opening the possibility of erasure extinction therapy. In contrast to the adult, extinction of fear memories appears to be erasure in nature in infant rodents. Here, we review the recent literature on fear extinction during development and identify the critical issues to be resolved. Understanding the mechanism of erase-type extinction in the young may enable more effective therapy to treat PTSD and/or anxiety disorders by preventing the return of fear permanently.
\end{abstract}

\section{Introduction}

Context-dependent modulation of learned skills or information is vital to the appropriate functioning of an organism. This modification allows an organism to change or update the stored information according to alterations in their values about and associations to the external world [1]. Such modifications are also important for treating psychiatric diseases, such as PTSD and anxiety disorders, by which exposure therapy has been effective in reducing the exaggerated fear responses to trauma-related cues or terrible memory in these patients [1-5].

In classical auditory fear conditioning, an auditory cue, the socalled conditioned stimulus (CS), is associated with an aversive shock, the unconditioned stimulus (US). When CS is presented in the absence of US, extinction occurs which is exhibited as reduction and eventual cessation of conditioned responses (freezing or startle in this case). Pavlovian fear conditioning in animals has been studied extensively to simulate various clinical features of anxiety disorders, including relapse of post-traumatic stress disorder (PTSD). It is generally viewed that PTSD is associated with elevated fear-memory acquisition, poor contextual gating of fear, and impaired learning and retention of fear extinction [6-11]. Extinction provides the biological basis of exposure therapy, in which patients are exposed to feared stimuli in a systematic, gradual manner with the aim to reduce fear responses to these stimuli. Therefore, understanding the formation and extinction of fear memory has a direct relevance to the treatment of PTSD and other anxiety disorders. Developmental theories as well as clinical and empirical evidence have increasingly shown very young children at critical developmental ages are more vulnerable to trauma than older children and adults [7-9]. They are more capable to extinguish previously learned associations which lead to more effective regulation of their emotions [10]. The prevalence of anxiety disorders is known to increase during late childhood and early adolescence [11]. While extensive research describes the developmental patterns of human fear in response to intrinsically threatening events, far less research examines developmental aspects of learned fears.
In this review, we outline the mechanisms implicated in fear extinction process, highlight main findings and unsolved questions about extinction of fear memory during development, and discuss nature underlying fear extinction of juvenile and the potential therapeutic application.

\section{Nature and mechanisms of fear extinction in the adult}

With extinction, there are two possible fates of the formed fear memory: erasure or suppression. Erasure is defined as reversing the established changes during fear memory formation and hence removal of fear memory, while with suppression fear memory is left intact but its expression if suppressed via formation of a new inhibitory memory [12]. If a fear memory is excessive to cause uncontrollable fear and hence hinders with normal functions of an organism/individual, it is desirable to removal it entirely via erasure to prevent its future expression. However, for the adequately expressed fear which improves the chance of survival, it is of more advantage to suppress it under the conditions where it is irrelevant but to allow its expression under the appropriate context. This renewal of fear avoids the relearning process (which is required for fear to reemerge if erasure occurs) and thus allows rapid expression of fear to facilitate the appropriate responses.

Works carried out on adult animals have identified key brain structures involved in fear memory extinction and underlying biological mechanisms. Considerable evidence has shown that extinction does not reverse the original learning but instead is an active learning process. That extinguished fear memory can reappear under three distinct conditions (renewal, reinstatement and spontaneous recovery) [13] is generally regarded as strong evidence that extinction involves context-dependent new learning $[14,15]$. Fear extinction and retrieval requires a complex neural circuit, including hippocampus

Correspondence to: Qiang Zhou, School of Chemical Biology and Biotechnology, Peking University Shenzhen Graduate School, Shenzhen, China, E-mail: zhouqiang@ pkusz.edu.cn

Received: June 29, 2017; Accepted: July 18, 2017; Published: July 20, 2017 
(HPC), medial prefrontal cortex (mPFC) and amygdala [16-19]. It is generally agreed that hippocampus takes contextual information for both contextual fear conditioning and the contextual gating of cued fear memory retrieval [20-22]. The medial prefrontal cortex (mPFC) is a critically involved in fear extinction [23] by regulating and integrating external information to guide the function of downstream brain regions [24]. The prelimbic (PL) region of $\mathrm{mPFC}$ receives direct inputs from the basolateral amygdala (BLA) and the ventral hippocampus, and it plays important role in the generation and expression of conditioned fear responses. The infralimbic (IL) of mPFC is associated with the suppression of conditioned fear responses via projections densely innervating clusters of GABAergic cells of the amygdala that are interspersed between the borders of basolateral amygdala (BLA) and CeA (referred to as intercalated cells (ITC) during extinction learning and extinction memory retrieval [25].

Basal and lateral amygdala is required for the acquisition, storage and expression of conditioned fear memory. Long-term potentiation (LTP) in the lateral nucleus of the amygdala is proposed as the underlying synaptic mechanism of associative fear memory [26], although there are unresolved issues and challenges to the amygdala LTP hypothesis of fear conditioning [27]. Amygdala LTP requires activation of N-methyl-D-aspartate (NMDA) subtype of the glutamate receptor, and extinction training leads to depotentiation of LTP by inducing AMPA receptor endocytosis [28]. Thus, fear conditioning and extinction are accompanied by an increase and decrease in synaptic activity in amygdale, respectively [29]. Density of dendritic spines was significantly increased in the fear conditioned group compared to the fear extinction group in BLA [30]. However, fear conditioning induced spine elimination while new formation occurs after extinction occur on the same dendritic branches in dorsal medial region of the frontal association cortex (FrA) [31] The fact that opposite structural changes occur after fear conditioning is interesting, since it suggests the exact direction of changes may differ pending on the regions involved.

\section{Fear extinction during development}

A number of studies suggested that fear extinction is erasure in nature in postnatal animals (such as pre-weaning age of postnatal 17 in rodents). It is unclear whether this erased memory in infants reflects a failure of storage or a failure of retrieval. The basic observations are of the following: Rats received extinction training at P17 did not exhibit a return of fear when tested in a context different from the extinction training (i.e., renewal) or following a pre-test stressor (i.e., reinstatement). In contrast, rats extinguished at P24 exhibited a return of fear in both situations (Kim and Richardson, 2010b). Our group has observed elevated activity in the HPC during extinction retrieval in the juvenile mice, which suggested that HPC is likely to be functioning at this age [32]. This context-independent in cued fear memory extinction retrieval in the juvenile is consistent with previous findings [16,3335]. We also found that the output portion of the circuitry mediating extinction retrieval (IL to BLA) to be functional while the inputs portion (HPC to PFC) is not. This lack of effective inputs may result in context-independent extinction retrieval. On the other hand, NMDA receptor antagonist MK-801 impairs extinction retention if extinction training was given at P24 but not at P17 [28]. In addition, Kim and Richardson have shown that neither NMDA receptors nor GABA receptors are necessary for extinction of learned fear in the P17 rat [36]. Thus, extinction in postnatal animals appears to follow mechanistically distinct mechanisms than the adult in that extinction appears to erase the formed fear memory.
Why does extinction in juvenile animals appear to be erasure while most studies indicate suppression of fear memory in the adult? The most likely explanation is that HPC and/or mPFC do not carry their required functions in the juvenile due to either themselves are immature or their connections with BLA (where the fear memory is located) is not strong enough. For the former, one possibility is that the immature HPC cannot encode the contexts or discriminate contexts to enable the context-specific suppression of fear memory (as what occurs in the adult). There are, however, three evidences against this possibility: (1) contextual fear memory is established around P14 in mice [33]. (2) Context pre-exposure study suggested that HPC can encode contexts, but could not make use of contextual information in fear memory formation in the young mice [37]. (3) Our results indicated that lack of activation in brain regions known to participate in fear expression (e.g., PL, BLA) using c-Fos staining after extinction retrieval in $\mathrm{P} 17$ mice.

For the latter possibility that the connections between BLA and HPC and/or mPFC are not strong enough to mediate this top-down control, the evidence is as follows: HPC encoding context is observed at P17. Recent studies [37] and our recent results provide compelling evidence that the hippocampus is functional for contextual learning as early as P17. However, its connection to the amygdale or other relevant brain structures may not yet be fully developed. This lack of effective inputs may result in context-independent extinction retrieval ${ }^{[38,39]}$. We suggest the most likely cause of the context-independent extinction retrieval is the immatureness of HPC-PFC-Amygdala connections. Our analysis raised the possibility that it is the immatureness of connections from HPC to PFC, rather than connections from PFC to BLA, is the key step in preventing context-dependent extinction retrieval. This also has been shown in fear conditioning, where pre-weaned rats (typically younger than P23), fail to exhibit contextually conditioned freezing 24 $\mathrm{h}$ after conditioning, despite their ability to freeze to an explicit cue [40]. One interesting and intriguing possibility raised by Richardson and colleagues is that by being isolated from other key brain regions involved in fear memory, extinction in the BLA-dominant circuitry is erasure in nature (removal rather than suppression of memory). They proposed that extinction in P24 involves hippocampal modulation of mPFC, which in turn controls BLA projections to the CeA [36].

\section{Important unresolved questions}

1. The stability of fear memory in the juvenile: there is clear evidence that fear memory in the young is not stable and may be quickly reduced after retrieval [41]. In theory, an unstable memory will be easier to be extinguished or even erased. But the biological basis underlying this fragile fear memory is unclear [42]. It could be possible, since there is not much conductivity between BLA and HPC or BLA and PFC in the young, the fear memory formed under this condition is sensitive to turn-over. It follows that connections to different and numerous brain regions enable the formed memory resistant to erasure, than the memory with only one representation in the BLA. Although it is widely believed that fear memory is stored in the BLA, the stored memory appears to have wide connections to other regions in the brain. It will be important to test this possibility, especially in the context that the potential benefits of segregating these connections to isolate the fear memory in order to facilitate its extinction or erasure.

2. Is the extinction process in the young/juvenile mechanistically distinct from that in the adult? As we have discussed, brain regions being activated during extinction is quite different between juvenile and the adult since there are much less number of regions involved in the 
juvenile [36]. This observation is consistent with the finding that in the young BLA is not much connected with other brain regions including HPC and PFC [28]. Then does the difference in brain regions indicate distinct underlying mechanisms? For example, it has been reported that fear extinction is associated with the reversal of synaptic plasticity and alterations in dendritic spines in the adult [30], but whether similar changes occur in the young has not been tested. If extinction in the young is erasure in nature, then reversal of synaptic changes associated with fear memory formation is expected, likely in the BLA. If this is the case, then one question to be addressed is whether similar changes occur in the BLA in both young and adult, but distinct changes occur in in the adult at many more brain regions than in the young.

3. Can the erasure type extinction be achieved in the adult? Since extinction appears to occur as BLA is isolated from the rest of the brain, the question can be asked is whether silencing connections with HPC and PFC or just one of them is sufficient to push fear memory to be erased. There are some suggestive of this possibility: (1) Fanselow and colleagues found that deficit of the IL, animals fail to distinguish between a dangerous, fear-conditioned context and a novel context suggests that $\mathrm{mPFC}$ is integral to the ability to determine whether fear should be expressed or inhibited in a particular environment [43]. In vivo recordings or imaging of IL activity in rat or vmPFC activity in human have shown increased CS-related activity during fear extinction memory recall (2) While dHPC was damage, the brain can compensate it by alternative circuits [44-46], restoring some of the essential elements of context-related learning and memory. In particular, pretraining lesions can overcome a deficit caused by post-training lesions of the DH in fear renewal $[37,47,48]$ (3) Previous findings have found that in the absence of the BLA, animals are able to form compensatory fear memories, provided they are given adequate training $[49,50]$. These findings support the idea that the fear system is comprised of interconnected, highly parallel circuits that provide compensatory plasticity in the event that one structure is compromised [51].

\section{Summary and conclusions}

There is clear evidence that fear memory in the young is not stable and may be quickly reduced after retrieval. But the biological basis underlying this likely erased fear memory is unclear. The observation that BLA is not much connected with other brain regions including $\mathrm{HPC}$ and PFC in the young may be the main reason. If this speculation is confirmed, the next question is whether something similar can be achieved or mimicked in the adult to enable erasure of unwanted fear memories and hence makes therapy more effective and persistent.

\section{Acknowledgments}

This work was supported by the Shenzhen Science and Technology Innovation Committee (Grant No. JCYJ20150629144658017) (Grant No. JCYJ20170306165021201) (Grant No. ZDSYS201504301539161).

\section{Conflict of interest}

The authors declare that they have no conflicts of interest with the contents of this article.

\section{References}

1. LaBar KS, Cabeza R (2006) Cognitive neuroscience of emotional memory. Nat Rev Neurosci 7: 54-64. [Crossref]

2. Boschen MJ, Neumann DL, Waters AM (2009) Relapse of successfully treated anxiety and fear: theoretical issues and recommendations for clinical practice. Aust $N Z J$ Psychiatry 43: 89-100. [Crossref]
3. Merikangas KR, He JP, Burstein M, Swanson SA, Avenevoli S, et al. (2010) Lifetime prevalence of mental disorders in U.S. adolescents: Results from the National Comorbidity Survey Replication-Adolescent Supplement (NCS-A). J Am Acad Child Adolesc Psychiatry 49: 980-989. [Crossref]

4. Maren S (2011) Seeking a spotless mind: extinction, deconsolidation, and erasure of fear memory. Neuron 70: 830-845. [Crossref]

5. Pattwell SS, Duhoux S, Hartley CA, Johnson DC, Jing D, et al. (2012) Altered fear learning across development in both mouse and human. Proc Natl Acad Sci U S A 109: 16318-16323. [Crossref]

6. Acheson DT, Geyer MA, Baker DG, Nievergelt CM, Yurgil K, et al. (2015) Conditioned fear and extinction learning performance and its association with psychiatric symptoms in active duty Marines. Psychoneuroendocrinology 51: 495-505. [Crossref]

7. Simpson JA, Griskevicius V, Kuo SI, Sung S, Collins WA (2012) Evolution, stress, and sensitive periods: the influence of unpredictability in early versus late childhood on sex and risky behavior. Dev Psychol 48: 674-686. [Crossref]

8. Hamiel D, Wolmer L, Pardo-Aviv L, Laor N (2017) Addressing the Needs of Preschool Children in the Context of Disasters and Terrorism: Clinical Pictures and Moderating Factors. Curr Psychiatry Rep 19: 38. [Crossref]

9. Slone M, Mann S (2016) Effects of War, Terrorism and Armed Conflict on Young Children: A Systematic Review. Child Psychiatry Hum Dev 47: 950-965. [Crossref]

10. Pattwell SS, Duhoux S, Hartley CA, Johnson DC, Jing D, et al. (2012) Altered fear learning across development in both mouse and human. Proc Natl Acad Sci U S A 109: 16318-16323. [Crossref]

11. Cohen P, Cohen J, Brook J (1993) An epidemiological study of disorders in late childhood and adolescence--II. Persistence of disorders. J Child Psychol Psychiatry 34: 869-877. [Crossref]

12. Quirk GJ, Paré D, Richardson R, Herry C, Monfils MH, et al. (2010) Erasing fear memories with extinction training. J Neurosci 30: 14993-14997. [Crossref]

13. Ji J, Maren S (2007) Hippocampal involvement in contextual modulation of fear extinction. Hippocampus 17: 749-758. [Crossref]

14. Bouton ME (2004) Context and behavioral processes in extinction. Learn Mem 11 485-494. [Crossref]

15. Bouton ME, Westbrook RF, Corcoran KA, Maren S (2006) Contextual and tempora modulation of extinction: behavioral and biological mechanisms. Biol Psychiatry 60: 352-360. [Crossref]

16. LeDoux JE (2000) Emotion circuits in the brain. Annu Rev Neurosci 23: 155-184 [Crossref]

17. Maren S (2001) Neurobiology of Pavlovian fear conditioning. Annu Rev Neurosci 24 897-931. [Crossref]

18. Quirk GJ, Mueller D (2008) Neural mechanisms of extinction learning and retrieval. Neuropsychopharmacology 33: 56-72. [Crossref]

19. Ehrlich I, Humeau Y, Grenier F, Ciocchi S, Herry C, et al. (2009) Amygdala inhibitory circuits and the control of fear memory. Neuron 62: 757-771. [Crossref]

20. Bouton ME, Westbrook RF, Corcoran KA, Maren S (2006) Contextual and temporal modulation of extinction: behavioral and biological mechanisms. Biol Psychiatry 60: 352-360. [Crossref]

21. Orsini CA, Kim JH, Knapska E, Maren S (2011) Hippocampal and prefronta projections to the basal amygdala mediate contextual regulation of fear after extinction. J Neurosci 31: 17269-17277. [Crossref]

22. Maren S, Phan KL, Liberzon I (2013) The contextual brain: implications for fear conditioning, extinction and psychopathology. Nat Rev Neurosci 14: 417-428. [Crossref]

23. Quirk GJ, Mueller D (2008) Neural mechanisms of extinction learning and retrieval. Neuropsychopharmacology 33: 56-72. [Crossref]

24. Thompson BM, Baratta MV, Biedenkapp JC, Rudy JW, Watkins LR, et al. (2010) Activation of the infralimbic cortex in a fear context enhances extinction learning. Learn Mem 17: 591-599. [Crossref]

25. Pinto A, Sesack SR (2008) Ultrastructural analysis of prefrontal cortical inputs to the rat amygdala: spatial relationships to presumed dopamine axons and D1 and D2 receptors. Brain Struct Funct 213: 159-175. [Crossref]

26. Yamada D, Wada K, Sekiguchi M (2016) Modulation of Long-Term Potentiation of Cortico-Amygdala Synaptic Responses and Auditory Fear Memory by Dietary Polyunsaturated Fatty Acid. Front Behav Neurosci 10: 164. [Crossref] 
27. Kim JJ, Jung MW (2006) Neural circuits and mechanisms involved in Pavlovian fear conditioning: a critical review. Neurosci Biobehav Rev 30: 188-202. [Crossref]

28. Kim JH, Richardson R (2007) A developmental dissociation of context and GABA effects on extinguished fear in rats. Behav Neurosci 121: 131-139. [Crossref]

29. Hong I, Song B, Lee S, Kim J, Kim J, et al. (2009) Extinction of cued fear memory involves a distinct form of depotentiation at cortical input synapses onto the lateral amygdala. Eur J Neurosci 30: 2089-2099. [Crossref]

30. Heinrichs SC, Leite-Morris KA, Guy MD, Goldberg LR, Young AJ, et al. (2013) Dendritic structural plasticity in the basolateral amygdala after fear conditioning and itsextinction in mice. Behav Brain Res 248: 80-84. [Crossref]

31. Lai CS, Franke TF, Gan WB (2012) Opposite effects of fear conditioning and extinction on dendritic spine remodelling. Nature 483: 87-91. [Crossref]

32. Foster JA, Burman MA (2010) Evidence for hippocampus-dependent contextual learning at postnatal day 17 in the rat. Learn Mem 17: 259-266. [Crossref]

33. Park CHJ, Ganella DE, Kim JH, et al. (2017) A dissociation between renewal and contextual fear conditioning in juvenile rats. Dev Psychobiol 59: 515-522. [Crossref]

34. Pattwell SS, Lee FS, Casey BJ (2013) Fear learning and memory across adolescent development: hormones and behavior special issue: puberty and adolescence. Horm Behav 64: 380-389. [Crossref]

35. Akers KG, Arruda-Carvalho M, Josselyn SA, Frankland PW (2012) Ontogeny of contextual fear memory formation, specificity, and persistence in mice. Learn Mem 19: 598-604. [Crossref]

36. Kim JH, Richardson R (2010) New findings on extinction of conditioned fear early in development: theoretical and clinical implications. Biol Psychiatry 67: 297-303. [Crossref]

37. Foster JA, Burman MA (2010) Evidence for hippocampus-dependent contextual learning at postnatal day 17 in the rat. Learn Mem 17: 259-266. [Crossref]

38. Rudy JW, Barrientos RM, O'Reilly RC (2002) Hippocampal formation supports conditioning to memory of a context. Behavioral neuroscience 116: 530-538. [Crossref]

39. Wiltgen BJ, Sanders MJ, Anagnostaras SG, Sage JR, Fanselow MS (2006) Context fear learning in the absence of the hippocampus. J Neurosci 26: 5484-5491. [Crossref]
40. Moriceau S, Raineki C, Holman JD, Holman JG, Sullivan RM (2009) Enduring neurobehavioral effects of early life trauma mediated through learning and corticosterone suppression. Front Behav Neurosci 3: 22. [Crossref]

41. Park CHJ, Ganella DE, Kim JH, et al. (2017) A dissociation between renewal and contextual fear conditioning in juvenile rats. Dev Psychobiol 59: 515-522. [Crossref]

42. Li S, Callaghan BL, Richardson R (2014) Infantile amnesia: forgotten but not gone. Learn Mem 21: 135-139. [Crossref]

43. Zelikowsky M, Bissiere S, Hast TA, Bennett RZ, Abdipranoto A, et al. (2013) Prefrontal microcircuit underlies contextual learning after hippocampal loss. Proc Natl Acad Sci U $S$ A 110: 9938-9943. [Crossref]

44. Wiltgen BJ, Sanders MJ, Anagnostaras SG, Sage JR, Fanselow MS (2006) Context fear learning in the absence of the hippocampus. J Neurosci 26: 5484-5491. [Crossref]

45. Zelikowsky M, Pham DL, Fanselow MS (2012) Temporal factors control hippocampa contributions to fear renewal after extinction. Hippocampus 22: 1096-1106. [Crossref]

46. Maren S, Aharonov G, Fanselow MS (1997) Neurotoxic lesions of the dorsal hippocampus and Pavlovian fear conditioning in rats. Behav Brain Res 88: 261-274. [Crossref]

47. Ji J, Maren S (2005) Electrolytic lesions of the dorsal hippocampus disrupt renewal of conditional fear after extinction. Learn Mem 12: 270-276. [Crossref]

48. Frohardt RJ, Guarraci FA, Bouton ME (2000) The effects of neurotoxic hippocampal lesions on two effects of context after fear extinction. Behav Neurosci 114: 227-240. [Crossref]

49. Ponnusamy R, Poulos AM, Fanselow MS (2007) Amygdala-dependent and amygdalaindependent pathways for contextual fear conditioning. Neuroscience 147: 919-927. [Crossref]

50. Maren S (1999) Neurotoxic basolateral amygdala lesions impair learning and memory but not the performance of conditional fear in rats. J Neurosci 19: 8696-8703. [Crossref]

51. Fanselow MS (2010) From contextual fear to a dynamic view of memory systems. Trends Cogn Sci 14: 7-15. [Crossref]

Copyright: (C2017 Li L. This is an open-access article distributed under the terms of the Creative Commons Attribution License, which permits unrestricted use, distribution, and reproduction in any medium, provided the original author and source are credited. 